\title{
BANDAS DE CONGO E POLÍTICA OFICIAL: CENÁRIOS DE TRADIÇÕES E TRANSFORMAÇÕES ESTÉTICAS CORPORAIS
}

\author{
DR. JOSÉ LUIZ DOS ANJOS
}

Departamento de Desportos, Centro de Educação Física e

Desportos, Universidade Federal do Espírito Santo

(Vitória - Espírito Santo - Brasil)

E-mail: jluanjos I@hotmail.com

\section{DR. OTÁVIO TAVARES}

Departamento de Ginástica, Centro de Educação Física e

Desportos, da Universidade Federal do Espírito Santo

(Vitória - Espírito Santo - Brasil)

E-mail: otavares@yahoo.com.br

\author{
MS. JULIANA GUIMARÃES SANETO \\ Programa de Pós-graduação em Educação Física, Faculdade de \\ Educação Física, Universidade Estadual de Campinas \\ (Campinas - São Paulo - Brasil) \\ E-mail: jsaneto@yahoo.com.br
}

\begin{abstract}
RESUMO
O objetivo foi analisar os grupos de congo do município de Vitória-ES, quanto aos elementos que os estruturam, como: expressões corporais, inserção de novos atores e a relação com o Poder Público. Foram utilizadas entrevistas abertas com três lideranças de grupos de congo e as análises pautaram-se nas categorias e conceitos identificados nas falas dos entrevistados, conforme Minayo (2007). Concluiu-se que há transformações no processo de expressões corporais advindos da entrada de novos atores nos grupos, entre esses os jovens, que introduziram novas estéticas corporais. A relação com o Poder Público possibilitou aos grupos se conhecerem e se relacionarem, aderindo a novos arranjos estéticos. Identificou funções e noções de papéis quanto ao gênero dos atores dos grupos analisados. Coletivamente as expressões corporais não possuem destinações de papéis, mas revelou que individualmente o congo as reproduz.
\end{abstract}

PALAVRAS-CHAVE: Congo; tradição; transformação cultural; expressão corporal. 
Ao identificar as diversas matrizes culturais e estéticas, e discutindo como elas se mostram e com quais características se apresentam, recorremos na Antropologia Social e Cultural para empreender as relações sociais e culturais numa região povoada por múltiplas faces culturais, como o Estado do Espírito Santo, neste estudo delimitado pelo município de Vitória.

A perenidade e continuidade dos elementos culturais se tornam difíceis num mundo globalizado no qual os recursos da comunicação estão em constante desenvolvimento, tendo a sociedade meios disponíveis e opções variadas de diversão e lazer. $\bigcirc$ interesse pelas tradições populares parece não ser um dos elementos capazes de figurar no universo de entretenimento no mundo urbano. No entanto, não podemos argumentar que esse campo não tem merecido ou não venha a merecer atenção e interesses de diversas áreas do mundo econômico e do Poder Público. Em efeito, basta analisar como as festas populares têm ganhado maior visibilidade com a espetacularização de suas performances estéticas, em que o popular, o tradicional se mistura de forma permanente com elementos modernos e técnicos (FARIAS, 2005).

Essa espetacularização é parte do problema aqui tratado, portanto diz respeito às ambivalências ocorridas nas imbricações estéticas e simbólicas das tradições e do moderno mundo urbano. Isso quer dizer que, nos espaços tradicionais que reúnem as práticas lúdicas e simbólicas, justamente no instante em que são inseridas em circuitos urbanos de massa, por meio das políticas públicas e da atuação da iniciativa privada, há redefinições dessas práticas, ocorrendo transformações nas instâncias que as legitimam: os significados simbólicos e as representações que permeiam e perpassam essas práticas.

Mas o que justifica e nos leva a discutir e estudar as manifestações e expressões corporais de grupos tradicionais, sabendo que a Educação Física tem se ocupado de outros campos e aplicabilidades, tendo o esporte como centro de suas atenções e estudos? Ocorre que, nas manifestações populares de cunho cultural, há fortes e incontáveis expressões corporais que vêm sendo transformadas e pedagogizadas, segundo Marques (2006), e este estudo contribuirá para o acúmulo de conhecimento da Educação Física brasileira.

Ainda justificando, por se tratar de um estudo longitudinal, intencionamos que as expressões corporais identificadas nos grupos de danças populares possam ser aplicadas transversalmente na prática de ensino da Educação Física escolar e na formação de graduandos dos cursos dessa área, garantindo possibilidades de sua contextualização. Embora se perceba que os estudos têm um caráter instrumental e embrionário, as conclusões não finalizam as discussões encontradas. 
Na formação da Região da Grande Vitória (Sec. XIX) por imigrantes italianos, negros e índios, a convivência, nem sempre pacífica, esteve relacionada com as questões do domínio cultural de um grupo pelo outro. $\bigcirc$ que queremos enfatizar é que a grande "guerra" se deu no campo simbólico, ou seja, no campo das esferas culturais que adentravam na materialidade subjetiva.

Para melhor analisar as características e singularidades das danças populares, é necessário que conheçamos o locus em que elas estão inseridas. As continuidades dessas manifestações têm sido pela oralidade e pelos movimentos gestuais. Para Bastide (1978), oralidade é toda maneira de pensar, sentir e agir que constitui uma expressão de experiência peculiar da vida de qualquer coletividade humana, integrada numa sociedade. Essa experiência tem sido preservada por meio da tradição oral, e grande parte dos elementos populares encontra-se retida e acondicionada na memória popular coletiva.

Os elementos tradicionais são complexos e repletos de simbologias, representando não somente o legado de nações africanas, como também os reinos sagrados e de simbologias indígenas. Nas festas, muitas celebrações, em seus rituais, dramatizam e incluem o levantamento de mastros, a produção de estandartes, a celebração de novenas, cortejos solenes, a coroação de reis e rainhas, o cumprimento de promessas, a realização de relações de parentesco, cantos, danças e banquetes coletivos. Embora esses elementos estejam presentes, nem todos os grupos de congo se manifestam apropriadamente com essas estruturas. Temos que entender que o estudo não pretende analisar se esses elementos ainda são constitutivos dos grupos a serem analisados, mas, minimamente, discuti-los no decorrer das análises a serem realizadas.

E o que as festas tradicionais da Região da Grande Vitória, sobre as quais estamos dissertando, apresentam em suas estruturas estéticas e simbólicas? São festas que mantêm entre si similaridades e diferenças construídas e cravadas em ritos originados de costumes que se fixaram no âmago de cada uma das manifestações, possibilitando a compreensão de suas particularidades. A festa em homenagem a São Benedito, na qual se reúnem as bandas de congo anualmente, no município da Serra-ES, é um exemplo típico da continuidade dessa força cultural. Não se trata aqui de falar de festas sagradas e profanas, embora possa parecer imperceptível ou insignificante, quando se observa de um modo superficial ou generalizado, porém, em nosso estudo, vimos que essa diferença é visível, primordial e é também geradora de discussões, portanto, essas festas devem ser tratadas com suporte metodológico-científico e amparadas por conhecimentos políticos e sociais. 
Problematizamos nosso estudo perguntando como se apresentam as faces culturais e estéticas existentes no município de Vitória, como os grupos de congo se apresentam e o que promove a continuidade dessas tradições? E, especificamente, qual a relação dos grupos de congo com o Poder Público? No processo de investigação, utilizamos como instrumento, a entrevista aberta com três líderes de grupos/ bandas de congo existentes em Vitória, tendo um roteiro com temas norteadores para identificar, na fala dos entrevistados, as relações sociais existentes entre os atores e o papel de cada um no grupo e, também, o imaginário coletivo e individual que permeia cada ator. Num segundo momento da entrevista, pretendemos identificar a relação das bandas de congo com o Poder Público local ou com instituições sociais.

Adotamos a entrevista aberta porque essa metodologia pode nos fornecer elementos objetivos e subjetivos considerando este último, possível de revelar atitudes, valores e visões políticas dos entrevistados e, segundo Minayo (2007), esse tipo de entrevista é utilizado na descrição e na compreensão de especificidades culturais para determinados grupos e para comparabilidade de diversos elementos culturais. As entrevistas abertas apresentam questões norteadoras, mas não são específicas nem fechadas. Apresenta um roteiro para que o pesquisador possa se dirigir, podendo haver a possibilidade de adição de novos questionamentos para compreender melhor determinado tema.

Para a análise das informações coletadas, partimos da compreensão de que os sujeitos informantes figuram de forma indissociável entre o mundo objetivo e o subjetivo (MINAYO, 2007). A interpretação das informações e a atribuição de significados são preposições da pesquisa qualitativa. Nesse sentido, dados coletados serão analisados indutivamente pelo pesquisador, pautando-se nas possíveis categorias e/ou conceitos identificados nas falas dos entrevistados.

\section{DISCUSSÃO TEÓRICA: OS OBJETOS DE ANÁLISE}

Diante dos objetivos propostos, investigamos e analisamos os grupos/ bandas de manifestações culturais em Vitória-ES e, de acordo com as informações fornecidas pela Secretaria de Cultura de Vitória, registramos os seguintes grupos/ bandas que se constituem na zona urbana de Vitória: Banda de Congo de Vitória; Banda de Congo Amores da Lua; Banda de Congo Mirim da llha; Banda de Congo das Paneleiras (denominado Panela de Barro); e Banda de Congo Mirim Estrelinha. A seleção para pesquisa das bandas de congo e suas lideranças, adotamos, como critério, a relação institucional das bandas de congo com o Poder Público e a atuação contínua das lideranças nessas bandas. 
Para colher informações, entrevistamos três lideranças, duas pertencentes à Banda Amores da Lua, que possui organização e atuação contínua, apresentando-se em locais públicos e em festas culturais e folclóricas, representando o município de Vitória, com forte presença feminina que a faz distinguir-se de outras bandas de congo. A terceira liderança pertence à Banda de Congo Panela de Barro, da comunidade de Goiabeiras, região conhecida pela tradição de se fazer panela de barro há mais de 300 anos, e uma das mais velhas bandas de congo da Grande Vitória. As entrevistas foram realizadas com os coordenadores, que são lideranças conquistadas pelo tempo de permanência nas bandas de congo, conforme informações dos próprios integrantes. Para chegar às lideranças, buscamos informações que constam na Secretaria de Cultura do Município de Vitória. Após os primeiros contatos em dias de ensaios ou nos dirigindo às residências, fomos apresentados aos coordenadores das bandas.

O primeiro líder, com $8 \mathrm{I}$ anos, está no grupo, de forma ininterrupta, desde 1981. A segunda liderança a ser entrevistada foi uma participante feminina de uma banda de congo, considerada, também, como líder do grupo. A terceira entrevistada está de forma contínua na banda há 13 anos, desde 1999. Essas lideranças estão participando de forma contínua ou ininterrupta, embora estejam há mais tempo na banda; no entanto, problemas de doença os levaram a se ausentar das atividades, como ensaios e viagens, e causaram afastamentos, principalmente das festas e das principais comemorações.

Para as entrevistas utilizamos câmeras e gravadores para colher as informações, tendo as seguintes perguntas: quais são os significados simbólicos que permeiam e permitem a participação dos atores na banda e que relações sociais são criadas nas interações sociais causadas pela participação na banda de congo? Qual a participação do Poder Público na continuidade das bandas de congo? Para identificar os informantes, eles foram denominados de: AI e A3 (liderança masculina) e A2 (liderança feminina). Realizamos as entrevistas em três momentos distintos e, em todos eles, os informantes não estavam sozinhos. Com Al e A3, as entrevistas foram realizadas nos locais de ensaios, e com A2 foi na sua residência, acompanhada de três vizinhas e um contingente de crianças.

Inicialmente, após apresentação, perguntamos o que faz/leva o sujeito, no caso participante/integrante, a participar da banda de congo. Para AI e A3: "É que todo mundo gosta de participar... Tem gente que está aqui desde muito tempo" e "É um jeito que as pessoas encontram pra se viver. Gosta de estar junto com outras pessoas". Segundo as lideranças, a convivência é o que faz as pessoas participarem das bandas. No entanto, quando perguntamos sobre a existência de algum motivo "especial", os mesmos informantes nos responderam: "Olha... todo 
mundo acredita... acredita em alguma coisa que faz a gente ficar junto... Quando é festa, todo mundo dá uma ajuda pra ninguém desanimar [...] mas eu vejo que tudo tá relacionado com a fé que a gente tem". Embora seja a fala das lideranças, a "fé" é um elemento comum que constitui as relações sociais, pois torna cada ator responsável pela continuidade do coletivo.

Perguntado o que mudou no grupo, num primeiro momento não obtivemos resposta, mas, explicando os detalhes, se houve mudanças na indumentária, cores, instrumentos, no "jeito de dançar", recebemos como respostas: "A roupa a gente mudou, mudou bastante, porque antes não tinha roupa fácil assim, hoje tem mais, a gente compra e a gente recebe dinheiro para comprar... quando vai apresentar fora, a gente recebe roupa nova", nos diz AI. Também A3 esclarece:

Os instrumentos continuam do mesmo jeito. Quando não tem couro, a gente arruma um couro emprestado de alguém e completa o instrumento, mas tudo continua o mesmo... Tem alguma música que a gente canta que foi mudando... A gente num notou, mas, quando viu, já tinha outra coisa cantando.

Considerando que o congo contemporâneo está no entrelugar de dança-costume e espetáculo ou na fronteira entre cultura popular e cultura para massa, pois, com a expansão cada vez mais intensa dos meios de comunicação e com a própria dinâmica das relações sociais, econômicas e culturais no País, a dança popular não só ganha novos elementos - vestimentas, acessórios, instrumentos - como também novos significados, e passa de uma produção artesanal para um produto destinado ao consumo de quem se constitui espectador das programações culturais populares. Para Canclini (2008), os "novos significados" são interessantes para o mercado, pois aponta novas criatividades, constituindo novos arranjos, pois o popular é o que vende, o que agrada multidões, e não o que é criado pelo povo. O que importa é o popular como popularidade. Aqui reside a inversão que vemos nas últimas décadas: o popular, que tinha o próprio povo como consumidor, hoje é elaborado e reelaborado para um público distinto de seus atores.

$\mathrm{Na}$ continuidade das análises, é interessante observar que o ritmo do congo é constituído por uma seção musical (três ou quatro tambores, flautas e canzás, ou casacas) e possui um conjunto de figurantes, todos eles dançarinos. É justamente esse ordenamento que interessa à Educação Física, que permite identificar a corporalidade dos atores. Perguntamos qual o ritmo do congo, a música e a coreografia. Para o informante Al : "Não tem coreografia, cada um dança do seu jeito, mas todo mundo dança no ritmo da batida do tambor... É um ritmo forte, uma batida forte [...]. Só quando tem apresentação fora da cidade, é que a gente faz fila, fica todo mundo do mesmo jeito, mas todo mundo dança do jeito da batida do tambor" e 
completa argumentando que "também não tem cantigas certas, todo mundo sabe as cantigas, mas não tem ela (cantiga/letra)". Essa batida do tambor é que promove o ritmo dos movimentos dos dançarinos. Cada qual com seu movimento, mas cadenciado pelo ritmo do tambor. No entanto, para A3:

\footnotetext{
Cada um tem seu jeito, mas é na batida do tambor, da casaca, que a gente dá os passos. Quem pode dar mais passo dá mais. Quando tem muitos jovens e a gente traz as crianças, daí tem um jeito diferente, cada um tem o seu lugar e vai andando, dançando atrás da bandeira. Na batida do tambor, você vai pra frente, pra traz, sozinho ou lado a lado. Tem hora que o ritmo é mais forte (mais rápido). Os jovens conseguem, eles fazem diferentes dos mais velhos, eles trazem passos diferentes para dança e fica bonito e a gente vai tentando imitar.
}

Vale refletir sobre a aprendizagem oral e sua hierarquia na modernidade. Ao revelar que não há cantigas escritas, especificamente neste estudo, mesmo utilizando uma visão antropológica de cultura, percebemos que existe uma hierarquia entre os capitais culturais (CANCLINI, 2008). A arte vale mais que o artesanato, pois essa tem registro e nominações; a cultura escrita mais que a transmitida oralmente, pois escrita não sofre mudanças, pois mesmos os saberes orais se constituindo como expressões simbólicas, têm posição secundária no processo de continuidade ou de transformação pelos seus próprios agentes, vindo a ser espaço de conflito, pois "[...] daí, quando saímos prá fora (apresentar em outro município) nem todo mundo gosta de decorar a música com palavras diferentes, informa Al .

Os campos das novas expressões e manifestações, de forma institucional, não podem ser identificados como únicos "responsáveis" pelas ressignificações e transformações, pois cada participante não é um mero espectador passivo de uma tradição secular sobre a qual não tem nenhum controle e só the cabe preservar. Pelo contrário, os participantes, e aqui, neste caso, os jovens que se constituem nos grupos de congo, também modificam e estão participando ativamente das relações de força e de transformação.

Santos (20 I I), ao analisar as transformações existentes nas expressões da dança Sussa, na comunidade quilombola de Kalunga-GO, percebeu que houve mudanças rítmicas e estéticas, pois observou-se um hibridismo cultural, pois o objeto analisado foi redimensionado. Isto é, buscou-se a dança Sussa e encontrou-se outra manifestação corporal, o forró. Para Santos (20 I I ), os jovens foram os protagonistas dessa ressignificação; foram os responsáveis por demarcar a relação entre a tradição e a modernidade. Em nosso estudo, parece que os atores jovens não têm compromissos com as normas e expressões simbólicas, mas muitos deles possuem conhecimento dos fundamentos do congo, de seus simbolismos e significados. Canclini (2008), utilizando o conceito de poder de M. Foucault, diz que as relações 
não costumam ser igualitárias, mas é evidente que o poder e a construção do acontecimento são resultado de um tecido complexo e descentralizado de tradições reformuladas e de intercâmbios modernos, de múltiplos agentes que se combinam.

Perguntamos se os ritmos de dançar, as coreografias, os movimentos são diferentes e recebemos como resposta que "[...] não há diferença de ritmo, do jeito de dançar, cada um dança do seu jeito, mas sempre com o ritmo do tambor" (A3) e completa $\mathrm{Al}$ : " [...] não existe um ritmo só... Um ritmo pra todo mundo. É que, quando a pessoa tem idade, seu ritmo é mais devagar, mas isso não fica feio, todo mundo dança". Em relação a isso, perguntamos se existe uma coreografia ou um ritmo diferente de dançar ou de se movimentar para homens e mulheres, e A2 disse que "[...] não existe, todos os ritmos são iguais. É a roupa que a gente usa que faz dar diferença". Para Al:

[...] a dança serve tanto para os homens como para as mulheres, não tem diferença e também não dança um com o outro. Não existe, como nas danças que tem por aí onde existe o par. Existe o homem que faz um jeito e a mulher que faz outro jeito de dançar. Todo mundo dança do seu jeito e o ritmo pra um é o mesmo que para o outro.

Aqui reside o fato de a dança do congo, na fala dos entrevistados, servir para ambos os gêneros, pois não caracteriza o que é papel da mulher e do homem quanto aos movimentos e ao ritmo colocados de acordo com a musicalidade. É interessante abordar essa questão, pois, com essas práticas, pode-se pensar em outros estilos de dança, mais comumente caracterizados como femininos ou masculinos, para que se faça uma reflexão sobre os motivos de tal associação, descaracterizando qualquer manifestação de gênero nos movimentos. Analiticamente falando sobre a indistinção de gênero quanto ao movimento corporal, trata-se do papel de cada ator na coletividade do grupo, contudo, individualmente, embora os movimentos distintos sejam tributados ao figurino, histórica e socialmente, os movimentos corporais na dança do congo estão sujeitos às construções sociais de gêneros.

A Antropologia Social vem abordando essa categoria, e entende a sua construção no interior das estruturas de relações de poder, onde atores sociais ocupam posições que implicam ordenações hierárquicas, que, embora pequenas nas esferas sociais, contêm a semente das relações de poder na sociedade (BUTLER, 2003).

Neste estudo, as posições ocupadas compreendem uma série de práticas e significados que thes conferem sentido, quando as expressões corporais se convertem em performances de gênero, ou seja, estilizam o corpo e repercutem na aparência e no comportamento de quem dança, produzindo e reproduzindo maneiras específicas de se viver a masculinidade e a feminilidade.

Em se tratando de cântico, musicalidade e coreografia, cada grupo possui sua performance estética, como o modo de tocar os tambores (guararás), que pode 
ser sentado sobre eles, como se estivessem cavalgando, e assim o fazem quando estão parados. A casaca e o chocalho, aos quais os negros ajuntaram a cuíca, são complementados por outros instrumentos: apito, triângulo (ferrinho), caixas, sanfonas (estas por influência da imigração italiana, que ocorreu no Espírito Santo), pandeiros e ganzás. Os instrumentos são pintados nas cores da banda.

Procuramos discutir com os nossos interlocutores acerca da escolha e da função de cada um no grupo, e eles disseram que "Os homens gostam de tocar... E os instrumentos são pesados para as mulheres" (A3). "Tem homem tanto com os instrumentos e também na dança" (AI). Isso não é decorrente de uma mentalidade de expressões, mas de papéis e de apropriações históricas vinculadas ao gênero, análise também consubstanciada por Dias (2012) que, em seus estudos com 24 bandas de congo no Espírito Santo, concluiu que só os homens tocam os instrumentos.

Para AI , A2 e A3, consubstanciados na fala de A2: "[...] os jovens vêm para o grupo quando a gente pede. Quando tem viagem pra fora, os jovens e as crianças vêm". Perguntamos quem são essas crianças, e os informantes Al e A3, na fala de A2, foram enfáticos: "Olha... Geralmente são netos, sobrinhos, filhos [...]". Pelas respostas, observamos que o grupo se constitui de membros de relação muito próxima, mesmo que não configure membro familiar de descendência, a relação e a proximidade familiar são notadas, conforme vemos nos depoimentos dos informantes: "Aqui, nesse grupo, tenho dois afilhados [...], eles já estão com 12 anos" (AI) e "Minha comadre, quando vem, ela traz meus afilhados [...] e "Daí, vem ela, o compadre e seus filhos" (A2).

Análises semelhantes encontraram Anjos e Souza (2006), ao identificarem que grupos de folia de reis se constituem de familiares ou de agregados próximos que manifestam continuidade parentesca. Assim, os encontros dos grupos de congo ou seus ensaios conservam a construção de laços familiares ou a continuidade de relações que perduram por décadas. Cada qual com sua história, "compadres, comadres, tios, netos, sobrinhos", constituem um emaranhado de parentescos permitido pelos encontros sazonais dos ensaios.

Perguntamos se o Poder Público (Prefeituras Municipais) tem colaborado com as bandas de congo, e os informantes AI e A3 disseram que "Quando a gente vai pra fora [outros municípios], as Prefeituras ajudam. Eles se preocupam se está faltando alguma coisa... Se os instrumentos estão bom... Se todo mundo está com roupa". Perguntamos porque o Poder Público tem essa preocupação. Eles responderam enfaticamente: "A gente representa a cidade, é por isso" e "Eles se preocupam e vai até alguma pessoa para que a gente não fique ‘preocupado '”, informa AI. Na continuidade, indagamos sobre as viagens que são realizadas e, como resposta, obtivemos: "Geralmente são marcadas pela Secretaria da Cultura", informa A3, e "No início do ano, a gente tem marcado para onde vamos e os ensaios começam". 
Informaram-nos que há apresentações realizadas na própria cidade em diferentes espaços públicos, permitindo que os grupos sejam conhecidos nos municípios como forma de dar identidade à cidade. Abrimos um recorte, para iniciar uma breve discussão, pois as "apresentações" abrem espaços que demandam uma gama de teorizações sociológicas. O lugar da cultura pelo Poder Público se justifica e se legitima nas propostas de revitalização das tradições culturais, discursos latentes nas políticas públicas dos governos municipais e estaduais. Essas políticas têm ocupado um importante lugar para a compreensão da dinâmica urbana contemporânea, pois promovem um fator diferenciador de preocupação do poder público com a cultura local urbana (BOTELHO, 1997). Nesse sentido, o patrimônio histórico, as tradições locais, a cultura local e outros elementos têm se transformado em mercadoria altamente valorizada no mundo urbano e vêm recebendo atenção do Poder Público local.

Embora nesta análise não respondamos às questões que envolvem políticas públicas na área cultural, ao menos problematizamos questões colocadas que permitem, panoramicamente, entender as relações que motivam o interesse do Poder Público pelos grupos tradicionais do município.

Diante dos cenários altamente competitivos pela comunicação, os municípios precisam se destacar por meio de um diferencial. A valorização da tradição e da cultura local tem sido um dos temas e cenários mais explorados, pois, entendendo que os modelos urbanos e os cenários não são distintos, constituindo-se cada vez mais um fator global similar, há necessidade de diferenciá-los, comprometendo-se com o local onde os aspectos culturais urbanos e os usos e costumes locais estejam no plano dos cenários de apresentação, como um marco diferenciador do município.

Embora, analiticamente, não é o nosso objetivo, poderíamos questionar se esse espaço é um campo rico de luta social ou de acomodação e perda do popular, do seu potencial de oposição ao pensamento "oficial" de cultura.

Pensamos que não, pois, como vemos nas informações, se analisarmos pela via das relações sociais, há uma intensa produção de novos arranjos estéticos e sociais que hierarquizam e promovem novas configurações de forças. Talvez precisemos de Chartier ( 1995) para explicar a colocação desse questionamento, pois no bojo das políticas amparadas pelo Poder Público, há uma nova força sendo construída, pois o popular não se efetiva nos objetos, nas coisas, mas nas práticas sociais promovidas pelos agentes que the dão novos arranjos.

Os encontros de grupos/bandas parecem ser o ponto principal de todo enredo, de manifestação e expressão individual de cada membro do grupo, segundo $A 2$, seguido por $A 3$.

A gente revê os colegas de outras cidades que faz tempo que não se vê e depois você vê se o nosso grupo está bom ou não. Tem grupo usando outros instrumentos que a 
gente ainda não usa... Tem grupo que tem até coreógrafo que ensaiam eles. As viagens são boas por essa causa.

Tal fala denota elementos discursivos subjacentes conscientes e inconscientes. Percebe-se uma tradição aliada ao espetáculo e à busca da gestualidade performática, porque, acima de tudo, há uma comercialização e uma publicização do popular, pois é necessário existir para resistir. O existir converteu-se em estratégias que garantem a performance na entrada de atores jovens ao grupo, pois a exibição de gestos performáticos e velozes, capazes de prender o olhar da assistência, despertar seu interesse e, quiçá, possibilitar o entusiasmo pela agenda cultural implica a performance física, garantida pelos atores que debutam os espaços nas apresentações públicas.

Embora fale por si, participar das agendas culturais, na perspectiva do patrocínio público, requer, antes de tudo, empreender uma gestualidade performática objetiva para impressionar o olhar do turista, do urbano, como forma de validação das transformações estéticas e de seu fazer cultural em frente a outros grupos.

Observa-se também que, atualmente, não só os grupos inseridos no contexto urbano passam por transformações em suas tradições de se manifestar coletivamente. Nessa linha de pensar as transformações da cultura popular como produto, sem dúvida, os grupos das zonas urbanas estão mais propensos a essas transformações. Anjos e Souza (2006), em seus estudos de grupos populares de danças tradicionais na região norte do Espírito Santo, viram que, mesmos nos grupos da zona rural, não havia um sequer, no espaço de suas pesquisas, que fosse "puro", intocado, como os próprios participantes falam, pois o congo já "nasce" híbrido, espaço de uma mistura de etnias, movimentos, expressões, frutos de suas respectivas culturas.

Outra transformação que denota as manifestações populares, em nosso caso, os grupos de congo do município de Vitória, são os processos de contrafluxo cultural. As danças, as expressões e, coletivamente, as manifestações transcendem a fronteira do local (comunidades) e passam para um contexto globalizado, territorialmente falando, e são apresentadas em festivais, hotéis, pousadas, órgãos públicos e em outros locais fora das "fronteiras" da comunidade.

A simbiose de relações territoriais e espaciais é uma preocupação recorrente em debates acerca do que ocorre quando o popular avança e se relaciona com outros meios sociais, e se vale dos meios técnicos e modernos para ganhar repercussão e difundir sua "cultura". Há certo ressentimento disseminado de que o "popular" deixaria de ser tradicional e perderia suas raízes com sua disseminação pelos mass media. Entendemos que essas ideias não deixam de ser um conservadorismo, que nega a circularidade de saberes e retira do popular seu caráter inovador, uma vez que o popular se apropria dos instrumentos modernos para se difundir na busca de um regionalismo mais abrangente e nacional. 
Como último questionamento da pesquisa, indagamos aos líderes sobre a percepção que têm das transformações, ou não, quando se encontram com outros grupos conhecidos. Como respostas sintetizadas, colhemos: "Mudou quase tudo" (AI , A2, A3), "Modo de cantar" (A2), "De roupas" (A2), "Figurinos (A2)", "Passos marcados"(A2). E o que não mudou: "[...] as pessoas continuam as mesmas..." (AI , A3), "não mudou o jeito da gente pensar... A gente ainda fala das mesmas coisas" (AI , A2), "fala do passado, como era antes" (AI), "fala do jeito da gente viver" (A3), "não mudou o jeito da gente e os outros de levar a vida, isso não mudou... isso está mudando muito pouco"(AI,A2. A3)

Podemos compreender, a partir dessa leitura, que é possível pensar e ampliar o conceito de transformação cultural para além de sua materialização, em objetos, estéticas e tradições. A transformação vamos encontrar nos modos de uso e das apropriações feitas dos novos arranjos construídos pelos sujeitos sociais. Embora o moderno transforme os objetos, essa transformação não substituiu a herança do passado e interações que promovem a continuidade simbólica e de significados.

Aqui cabe essa questão ao nosso estudo, pois devemos refletir sobre a cultura, fazer experiências com ela, discuti-la e publicar os achados. Com esse argumento, o importante não é o objeto modificado (as danças, expressões, instrumentos), mas sim as interpretações e/ou reinterpretações, os novos signos que irão se constituir em novos significados ou que serão ressignificados.

\section{PARTINDO PARA A "DANÇA" FINAL}

Ao final deste trabalho, as considerações conclusivas podem ser apontadas nas especificidades de cada objeto analisado. Por se tratar de um estudo de matrizes socioantropológicas, as questões afeitas às relações sociais são as primeiras em que descortinamos as tradições pelas quais os grupos de congo se constituem. As relações de parentesco garantem aos atores das bandas de congo, aproximações familiais constituídas no decorrer das relações sociais. São essas aproximações que, num segundo momento, o das relações entre os atores, o estudo apontou como a "festa", aqui identificada com os ensaios e apresentações performáticas. São nas festas que ocorrem os contextos para a continuidade das relações permeadas pelos elementos do imaginário social. Esse imaginário constitui a devoção individual dos atores, dado pelo caráter não institucionalizado da fé, garantindo a reciprocidade e a continuidade do mundo social do grupo (MAUSS, 2003).

O estudo revelou implicitamente que o congo reproduz funções e papéis de gêneros, pois os instrumentos musicais são pertinentes ao homem, embora as falas dos entrevistados não tenham nitidamente desenhado tal face. Com efeito, a fala da 
liderança A2 indica percepções de parentescos nas relações do grupo, e também de elementos estéticos, como cantos, ritmos e figurinos. Quanto aos gestos e expressões corporais, que, na fala dos entrevistados foram explicitados como "dança", eles não revelaram que os gestos e expressões são desempenhados distintamente pelos atores dos grupos. Contudo, o estudo, analiticamente, não descaracterizou que as expressões corporais são elementos constituídos histórica e socialmente, logo, distinto a cada gênero.

Em uma análise conclusiva, podemos ver que os espaços ocupados pelas tradições populares, no caso o congo, nas agendas públicas, correspondem a iniciativas destinadas às políticas públicas com o objetivo de preservar identidades culturais ameaçadas de estagnação, quando situadas em locais de constantes transformações, como é o caso cosmopolitano em que se encontram esses grupos populares.

De outra forma, essas agendas, pautadas e avalizadas pelas asas do econômico, funcionam também como alavancas para a renovação dos modos de pensar e sentir de grupos que, embalados pela conjuntura do mundo moderno e tecnologizado, refluem à incorporação de novidades e avanços estéticos. De certa forma, a relação com outros grupos pode resultar, por exemplo, na transformação, como vem acontecendo com as mudanças, quando percebemos novos instrumentos e o uso de novas coreografias. Até por conta da realidade, os atores dos grupos de congo não vêem suas manifestações como uma cultura estagnada - com ideias de "perda" da raiz, das tradições - e nem como um produto para ser vendido, tendo que "transformar" para agradar.

Contudo, os estudos apontaram que os grupos de congo vêm passando por um processo de interação entre tradição e transformaç̧ão. Nesse contexto, o congo, como expressão e manifestação, vem ganhando elementos estéticos, principalmente resultantes de novos atores que se inserem nos grupos: os jovens e crianças.

Além do deslocamento das apresentações, que permitem novos arranjos e mudanças na sua composição estética, notamos que existem inserções institucionais que, diante de políticas de promoção da cultura popular, promovem uma descontinuidade de tradições, permitindo mudanças que imbricam na elaboração e incorporação de novas interpretações e novas construções simbólicas.

Com referência à tradição e à transformação, finalizamos nossos estudos entendendo que, por se tratar de uma questão no âmbito da cultura, é preciso refletir sobre a tradição e a transformação como faces complementares e não excludentes entre si, pois tradição não implica numa recusa à mudança e ao movimento (BALANDIER, 1997), da mesma forma que a modernidade não exige a extinção das tradições. 


\section{Band of Congo and the Official Politics: Sceneries of Traditions and Body Esthetic Transformation}

ABSTRACT: The objective was to analyze groups of congo in the city of Vitória - State of Espírito Santo, regarding their structure elements, such as: body expressions, introduction of new actors and their relation with the Government. An open interview was conducted with three leaders and the analysis were guided according to categories and concepts identified in the answers of the interviewees, according to Minayo (2007). The results showed that the introduction of new actors in the group caused transformation in the body expressions among these young people and their relation with the Government, which enabled the groups to acquire new body esthetics. Functions and participation of the actor role type in the analyzed groups were identified. Collectively, the body expressions do not have destination of role types, but, individually, congo reproduces it.

KEYWORDS: Congo; Tradition; Cultural Transformation; Body Expression.

\section{Bandas de congo y política oficial: escenarios de tradiciones y transformaciones estéticas corporales}

RESUMEN: El objetivo fue analizar los grupos de congo del municipio de Vitória-ES, en cuanto a los elementos que los estructuran, como: expresiones corporales, inserción de nuevos actores y la relación con el Poder Público. Se utilizaron entrevistas abiertas con tres liderazgos y los análisis se pautaron en las categorías y conceptos identificados en las conversaciones con los entrevistados, conforme a Minayo (2007). Se concluye en que hubo transformaciones en las expresiones corporales devenidas de la entrada de nuevos actores en los grupos, entre esos los jóvenes y la relación con el Poder Público posibilitó a los grupos adherir a nuevos arreglos estéticos. Identificó funciones y nociones de papeles en relación con el género de los actores de los grupos analizados. Colectivamente las expresiones corporales no poseen destinaciones de papeles, pero individualmente el congo las reproduce.

PALABRAS CLAVE: Congo; tradición; transformación cultural; expresión corporal.

\section{REFERÊNCIAS}

ANJOS, J. L.; SOUZA, R. O. Folia de reis: representações de uma comunidade de pescadores. Lecturas Educación Física y Deportes, Buenos Aires, ano II, n. 99, ago. 2006.

BALANDIER. G. O contorno: poder e modernidade. Rio de Janeiro: Bertrand Brasil, 1997.

BASTIDE. R. As religiões africanas no Brasil: contribuição a uma sociologia das interpenetrações das civilizações. São Paulo: Edusp, 1978.

BOTELHO, I. A diversificação das fontes de financiamento para a cultura: um desafio para os poderes públicos. In: MOISÉS, J. A.; BOTELHO, I. (Org.). Modelos de financiamento da cultura. Rio de Janeiro, Minc/Funarte, 1997.

BUTLER, J. Problemas de gênero: feminismo e subversão da identidade. Rio de Janeiro: Civilização Brasileira, 2003. 
CANCLINI, N. G. Culturas híbridas: estratégias para entrar e sair da modernidade. São Paulo: Ed. da USP, 2008.

CHARTIER, R. Cultura popular: revisitando um conceito historiográfico. Estudos Históricos, Rio de Janeiro, v. 8, n. 16, 1995.

DIAS, S. O. O negro no Espírito Santo: histórica do congo. Disponível em: <www.ape.es.gov. br/espiritosanto_negro/historia_congo.htm. >. Acesso em: 12. fev. 2012.

FARIAS, E. Economia e cultura no circuito das festas populares brasileiras. Educação e Sociedade e Estado, Brasília, v. 26, n. 3, p. 647-688, set./dez. 2005. Disponível em: <www.scielo.br/ scielo.php?pid=S>. Acesso em: 4 out. 2010.

MARQUES, I. A. Dançando na escola. São Paulo: Cortez, 2006.

MAUSS, M. Sociologia e antropologia. São Paulo: Cosac \& Naify, 2003.

MINAYO M. C. O desafio do conhecimento: pesquisa qualitativa. Rio de Janeiro: Abrasco, 2007

SANTOS, M. P. O. As representações sociais das práticas corporais na comunidade Kalunga - GO. 20। I. I0I f. Dissertação (Mestrado em Educação Física) - Universidade de Brasília, Brasília, 2011.

Recebido em: 27 fev. 2012

Aprovado em: 18 jul. 2012

Endereço para correspondência:

José Luiz dos Anjos

Avenida Fernando Ferrari, 5।4

Goiabeiras

Vitória, ES

CEP: 29910-900 